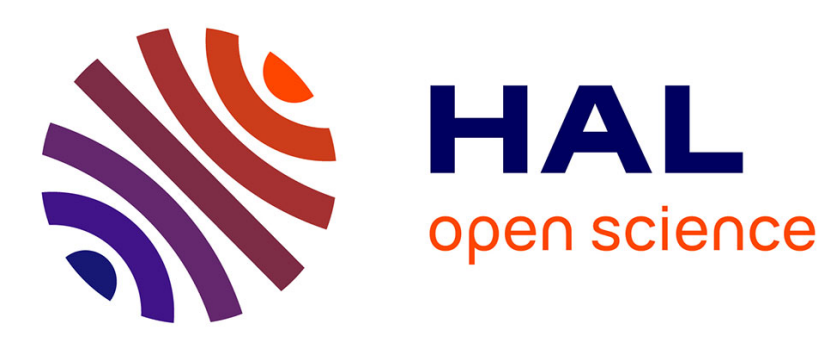

\title{
HEAT TRANSFER AND FLOW IN A HYDROGEN PLASMA REACTOR
}

\author{
F. Kassabji, Pierre Fauchais
}

\section{To cite this version:}

F. Kassabji, Pierre Fauchais. HEAT TRANSFER AND FLOW IN A HYDROGEN PLASMA REACTOR. Journal de Physique Colloques, 1979, 40 (C7), pp.C7-321-C7-322. 10.1051/jphyscol:19797158 . jpa-00219133

\section{HAL Id: jpa-00219133 https://hal.science/jpa-00219133}

Submitted on 1 Jan 1979

HAL is a multi-disciplinary open access archive for the deposit and dissemination of scientific research documents, whether they are published or not. The documents may come from teaching and research institutions in France or abroad, or from public or private research centers.
L'archive ouverte pluridisciplinaire $\mathbf{H A L}$, est destinée au dépôt et à la diffusion de documents scientifiques de niveau recherche, publiés ou non, émanant des établissements d'enseignement et de recherche français ou étrangers, des laboratoires publics ou privés. 


\section{HEAT TRANSFER AND FLOW IN A HYDROGEN PLASMA REACTOR}

\section{F. Kassabji, P. Fauchais.}

Laboratoire de Thermodynamique, U.E.R. des Sciences, 123, wue Albert Thomas, 87060 Limoges cedex, France.

\section{INTRODUCTION TO THE PROBLEM.}

The heat transfer from thermal plasmas to reactor walls is of major importance for the design of plasma generators or furnaces.

We propose to model a D.C. cylindrical plasma reactor working with hydrogen and defined by the following zones (figure 1 ).

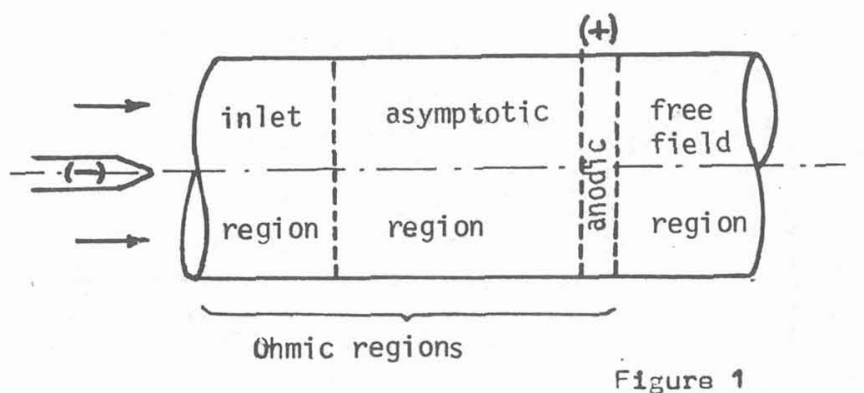

In the inlet region, the cold gas injected near the cathode is heated and ionised with no contact with cold walls.

The asymptotic region constitutes the region of flow development and stabilisation constricted by contact with energetically cooled walls. The increase of the ohmic energy, and therefore the gas temperature terminates in the anodic attachment zone (which we assume to be localised before the turbulent zone created by the development of plasma flow). In this zone the plasma gas transfers a part of its energy to the anode. Finally, the flow becomes steady in the free field region where the wall is cooled in a homogeneous way.

Assuming the hypothesis of the LTE we have solved the "Electro-Magneto-Dynamic" equations system $/ 2 /$ by a numerically finite difference method /3/ adapted /4/ to hydrogen plasma flow in a reactor with ohmic energy contribution. The computation programme is executed on an IBM 360/91 Computer. II. NUMERICAL RESULTS.

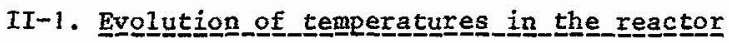
The isotherms (figure 2) give the evolution of the temperature in a cylindrical canal of $12 \mathrm{~mm}$ diameter, for a current intensity of 200Amp, and a hydrogen flow rate of $1501 / \mathrm{mn}$. The temperature profile in the entrance of the canal is assumed to be parabolic, but its influence is only important on first stages of flow. The temperature is maximum at the begining and on the axis of the anodic zone where the arc strikes the waIl and where the isotherms are radially attracted to the canal wall, while the hot core is growing.

After this anodic region, the plasma flows without additional heating source, the gas loses energy and cools progressively.

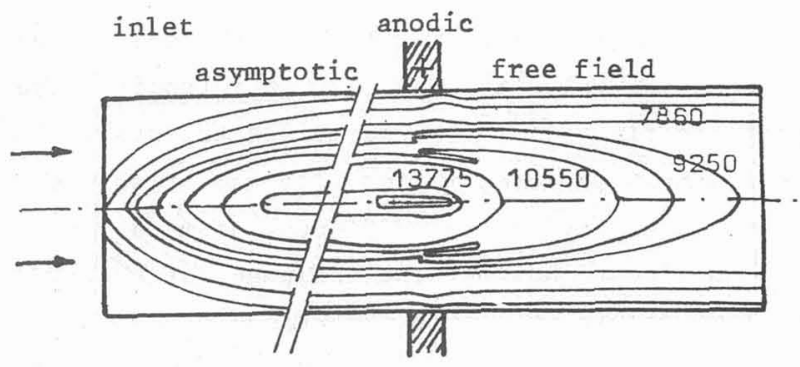

Figure 2

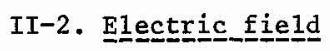

The electric field in the plasma is a function of the gas nature. We notice (figure 3 ) that it varies only very little with the cylindrical canal diameter and almost not at all with the axial position, except at the entrance of the canal where the influence of the electrical conductivity is very important. It therefore tends to a constant asymptotic value " $E_{x, a}$ " which is independent of the gas flow rate.

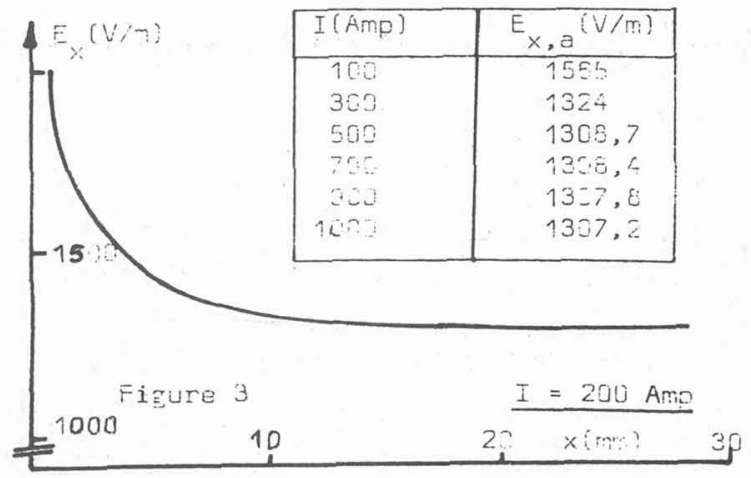




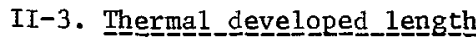

The "Thermal developed length $\mathrm{L}_{D}$ " is defined as the axial distance between the upstream of the cylindrical canal and the section where the average temperature reaches $90 \%$ of its asymptotic value.

This length is important for the "constrictor" design. We observe (figure 4) that it decreases with increasing current intensity; it also increases with the gas flow rate and is rather insensitive to diameter variation.

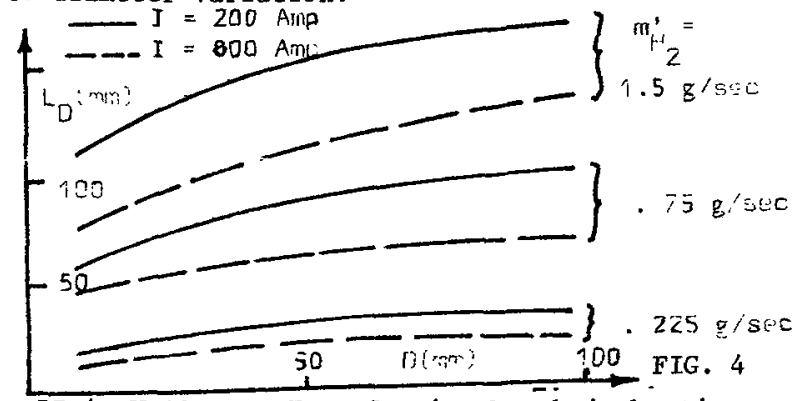

II-4. Wa11 Heat Trans gions.

We see that the heat flux on the wall tends to a constant value for any current intensity. The asymptotic flux " $\varphi_{\mathrm{T}, \mathrm{a}}$ " characterises the stabilised flow in the asymptotic region. Its variation with the arc intensity and the different diameters of the canal is linear, however the influence of the hydrogen flow rate is of little importance.

The Nusselt number in these heating regions of the constricted arc seems to be a function of the ohnic heating number "OH" $/ 5 /$. It increases (figure 5) with diminution of the ohmic heating number and leads to a relatively constant value with increase of "OH". We see also its increase with arc intensity, this augmentation tends to become relatively $1 i-$ near for the big diameters. Moreover, Nu appears irregular at first in the upstream region of the canal but stabilises afterwards and reaches the constant values defined previously.

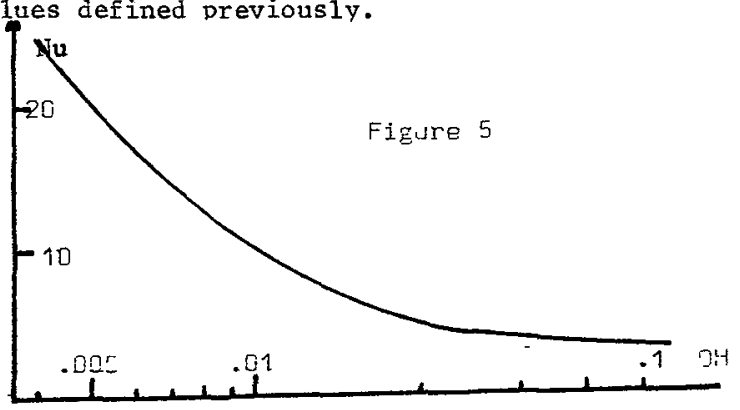

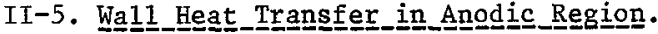

The wall heat transfer in the anodic zone is based upon an energy balance $16 /$. The transfer due to the electrons have been calculated at $10000^{\circ} \mathrm{K}$ ac- cording to the expression given by $/ 7 /$, the terms of the ablation and of the radiation of the anode have been neglected, but the convective and radiative exchanges have been approximated by the quantity of the heat calculated at the end of the asymptotic zone.

From the expressions we have determined the anodic heat flux " $\varphi_{A}$ " which increases with the intensity of the current and varies as the inverse of the diameter of the constriction canal.

Furthermore the increase of Nusselt number with are intensity becomes more important as the diameter of the constriction canal is increased. We also observe (figure 6) its increase with the decrease of the ohmic heating number " $\mathrm{OH}_{4}$ ".

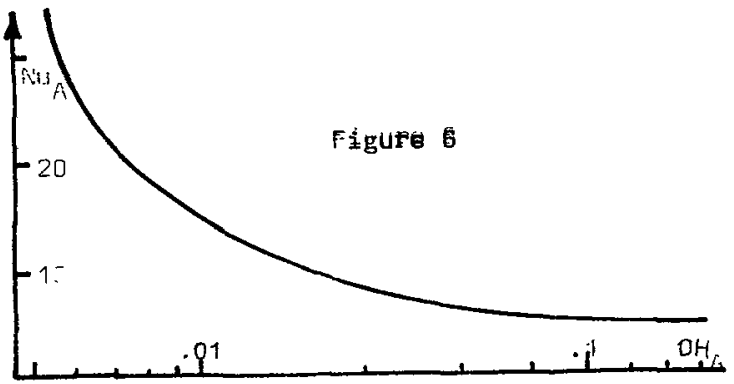

III. CONCLUSION.

The various calculations (by a finite difference method) for a cylindrical plasma reactor working with hydrogen for different diameters ( 5 to 50 $\mathrm{mm}$ ) and different intensities of the arc current (up to 1000 Amp) have allowed the determination of the necessary parameters for the design of plasma generators or reactors working under these conditions. REFERENCES.

/1/ JOUKOV M.F., KOROTIEIEV A.S., OUPIOUKOV B.A., Dynamique Appliquée du P1asma Thermique (1975)

/2/ KASSABJI F., Thèse 3ème cycle, Limoges (1975)

/3/ SPALDING D.B. et al, Heat and mass transfer in recirculating flows, Academic Press (1969).

14/ FAUCHAIS P., AUBRETON J., KASSABJI F., PATEYRON B., Rapport C.E.A., SA 5323, oct. (1976)

/5/ LUKENS L.A., INCROPERA F.P., Int. J. Heat Mass Transfer, 15, 935-951 (1972).

16/ SHIH K.T., PFENDER E., AIAA Jr1. 8,211 , (1970)

/7/ WUTZKE S.A., PFENDER E., IAAA Jr1. 6, 1474 (1968). 